\title{
花铃期渍水对棉纤维糖代谢的影响及其与纤维比强度的关系
}

\author{
杨长琴 1,2 刘瑞显 $^{2}$ 张国伟 $^{2}$ 杨富强 ${ }^{2}$ 周治国 ${ }^{1, *}$
}

1 南京农业大学农学院 / 农业部南方作物生理生态重点开放实验室, 江苏南京 $210095 ;^{2}$ 江苏省农业科学院经济作物研究所, 江苏南 京 210014

摘 要: 以美棉 33B 为材料, 2007 年和 2009 年在江苏南京池栽条件下设置渍水试验, 研究花铃期渍水对棉纤维糖代 谢的影响及其与纤维比强度的关系。结果表明, 渍水条件下花后 17 38d 纤维蔗糖和 $\beta-1,3$-葡聚糖含量均值分别降低 $24.86 \%$ 81.30\%和 $8.59 \%$ 36.30\%, 纤维素最大累积速率在受渍害较轻条件下增加而受渍害较重条件下降低, 但快速 持续期缩短, 成熟期纤维素含量降低, 比强度下降 3.57\% 10.03\%。受渍害较轻条件下, 花后 17 38 d 纤维熫糖合酶 (SS)和庶糖磷酸合酶(SPS)活性均值分别增加 8.45\% 24.59\%和 $12.79 \%$ 18.20\%, 生成碳源用于维持生存代谢, 而受渍 害较重条件下分别降低 7.06\% 8.16\%和 $11.40 \%$ 11.64\%; 蔗糖酶和 $\beta-1,3$-葡聚糖酶活性在花后 $17 \mathrm{~d}$ 后降低。因此，渍 水条件下纤维加厚发育期碳源供应不足、碳代谢消耗增加或代谢被抑制是最终比强度下降的重要原因。

关键词：棉花；花铃期；渍水；纤维相关物质和酶；纤维比强度

\section{Sugar Metabolism and Its Relationship with Fiber Strength Affected by Wa- terlogging during Flowering and Bolling Stage in Cotton}

\author{
YANG Chang-Qin ${ }^{1,2}$, LIU Rui-Xian ${ }^{2}$, ZHANG Guo-Wei ${ }^{2}$, YANG Fu-Qiang ${ }^{2}$, and ZHOU Zhi-Guo ${ }^{1, *}$ \\ ${ }^{1}$ Key Laboratory of Crop Physiology \& Ecology in Southern China, Ministry of Agriculture / Nanjing Agricultural University, Nanjing 210095, China; \\ ${ }^{2}$ Institute of Industrial Crops, Jiangsu Academy of Agricultural Sciences, Nanjing 210014, China
}

\begin{abstract}
The experiments were conducted using a cotton cultivar NuCOTN 33B with pool culture under different waterlogging treatments in 2007 and 2009 to study effects of waterlogging on carbohydrate metabolism and its relationship with fiber strength during flowering and bolling stage in Nanjing, China. The results showed that the mean values of sucrose and $\beta-1,3$-glucan contents decreased by $24.86 \%$ to $81.30 \%$ and $8.59 \%$ to $36.30 \%$ respectively at 17 to 38 days after anthesis under waterlogging. The maximum rate of cellulose accumulation increased in response to mild waterlogging conditions, decreased in response to serious conditions, but the duration of maximum cellulose accumulation shortened, which resulted in the decrease in cellulose content. The value of fiber strength at mature period decreased by $3.57 \%$ to $10.03 \%$ under waterlogging. The mean values of SS and SPS activities increased by $8.45 \%$ to $24.59 \%$ and $12.79 \%$ to $18.20 \%$ respectively in response to mild waterlogging conditions, but decreased by $7.06 \%$ to $8.16 \%$ and $11.40 \%$ to $11.64 \%$ respectively at 17 to 38 days after anthesis in response to the serious waterlogging conditions, which were due to enhanced metabolic demands. Waterlogging decreased the activities of sucrase and 3-1,3-glucanase after 17 days after anthesis. Therefore, insufficient carbon source, together with the increased carbon consumption or the inhibited sugar metabolism were potential factors contributing to low fiber strength for waterlogging plants.

Keywords: Cotton (Gossypium hirsutum L.); Flowering and bolling stage; Waterlogging; Key matters and enzymes; Fiber strength
\end{abstract}

纤维比强度是重要的原棉品质指标，除基因型 外, 环境因子如温度、土壤水分等对其影响也很大 ${ }^{[1-2]}$ 。 纤维比强度取决于纤维发育过程中纤维素累积特性, 而纤维素的累积实质是纤维中糖代谢循环的过程 ${ }^{[3-4]}$ 。
因此，研究纤维发育过程中糖代谢生理特征及其对 环境因子的响应, 对阐明纤维比强度的生态响应机 制及高比强棉花栽培具有重要意义。

蔗糖是纤维发育糖代谢的初始底物, 决定着纤

\footnotetext{
本研究由国家自然科学基金项目(31171487, 31371583)资助。

*通讯作者(Corresponding author): 周治国, E-mail: giscott@njau.edu.cn, Tel: 025-84396813

第一作者联系方式: E-mail: ychq2003@qq.com

Received(收稿日期): 2014-02-24; Accepted(接受日期): 2014-06-16; Published online(网络出版日期): 2014-07-09.

URL: http://www.cnki.net/kcms/detail/11.1809.S.20140709.1532.009.html
} 
维素合成的直接底物一一尿苷二磷酸葡萄糖(UDPG) 的生成速率 ${ }^{[-6]}$; 非纤维素物质 $\beta-1,3$-葡聚糖(胼胝质) 合成和降解也调节着纤维素的累积 ${ }^{[7]}$ 。纤维糖代谢 过程中蔗糖合酶分解蔗糖成 UDPG 和果糖, 为纤维 素的合成提供直接底物 ${ }^{[8]}$, 蔗糖磷酸合酶利用胞质 中游离态 UDPG 为供体催化合成蔗糖 ${ }^{[8-9]}$, 间接地调 节纤维素的合成。蔗糖酶水解蔗糖为葡萄糖和果糖, 为纤维素合成提供碳源和能量 ${ }^{[8,10]}$; 此外, $\beta-1,3$-葡 聚糖酶水解胼胝质, 降解的产物在增加细胞壁可塑 性同时为纤维素累积提供直接底物 ${ }^{[11]}$ 。因此, 纤维 发育过程中相关物质以及酶是影响糖代谢进程的重 要因子。已有的研究表明温度 ${ }^{[12]}$ 、氮肥 ${ }^{[13-14]}$ 影响纤 维发育的物质和酶活动态, 改变纤维素的累积特性, 致使纤维比强度下降。但未见有关花铃期渍水影响 纤维比强度生理机制的报道。本文通过研究花铃期 渍水对纤维发育糖代谢影响及其与纤维比强度的关 系, 揭示花铃期渍水影响纤维比强度的糖代谢生理 机制, 可为生产上制定栽培调节措施以及高强纤维 品种选育提供理论依据。

\section{1 材料与方法}

\section{1 试验设计}

试验于 2007 年和 2009 年在江苏南京江苏省农 业科学院防雨棚水泥池中进行, 供试土壤为黄棕壤 土。两年 $0 \sim 20 \mathrm{~cm}$ 土壤含有机质 $15.3 \mathrm{~g} \mathrm{~kg}^{-1}$ 和 $14.3 \mathrm{~g}$ $\mathrm{kg}^{-1}$; 全氮 $0.8 \mathrm{~g} \mathrm{~kg}^{-1}$ 和 $0.9 \mathrm{~g} \mathrm{~kg}^{-1}$; 碱解氮 $63.4 \mathrm{mg}$ $\mathrm{kg}^{-1}$ 和 $52.6 \mathrm{mg} \mathrm{kg}^{-1}$; 速效磷 $29.9 \mathrm{mg} \mathrm{kg}^{-1}$ 和 $23.8 \mathrm{mg}$ $\mathrm{kg}^{-1}$; 速效钾 $107.5 \mathrm{mg} \mathrm{kg}^{-1}$ 和 $93.2 \mathrm{mg} \mathrm{kg}^{-1}$ 。供试品 种为美棉 33B。2007 年 4 月 17 日播种、5 月 17 日 移栽, 2009 年 4 月 25 日播种、 5 月 22 日移栽; 2 年 种植密度分别为每公顷 3.60 万株和 3.90 万株。

2007年设对照和渍水 14 d 2个处理, 2009年设对 照、渍水 $7 \mathrm{~d}$ 和渍水 $14 \mathrm{~d} 3$ 个处理。对照土壤相对含 水量 (土壤相对含水量 $=$ 土壤含水量/田间持水量)保 持在 $(75 \pm 5) \%$; 渍水处理保持地面 $2 \sim 3 \mathrm{~cm}$ 水层, 渍水 结束后土壤相对含水量自然减少至 $(75 \pm 5) \%$ 。于中部 6 8台果枝开花时渍水处理, 开始处理时标记第 1 、 第2果节当日花和花后 $10 \mathrm{~d}$ 棉铃, 自花后 $10 \mathrm{~d}$ 起每 $7 \mathrm{~d}$ 取发育一致的棉铃 6 8 个(上午9:00至 10:00取样), 将纤维与种子分离后, 液氮速冻并在 $-30^{\circ} \mathrm{C}$ 下保存 以供测定酶活性。标记棉铃吐絮时, 收取大小一致 的棉铃约 20 个, 风干轧花后测定 $3.2 \mathrm{~mm}$ 隔距纤维 比强度。

\section{2 测定内容与方法}

用间苯二酚显色法 ${ }^{[15]}$ 测定蔗糖含量; 用苂光分 光光度计法 ${ }^{[16]}$ 测定 $\beta-1,3$ - 葡聚糖含量; 参照 Updegraff方法 ${ }^{[17]}$ 并略有改进，测定纤维素含量。用 熫糖和UDP比色法测定熫糖合酶 (SS) 活性(降解方

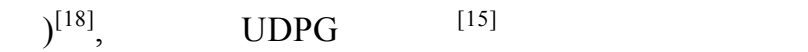
(SPS)活性; 用DNS显色法 ${ }^{[15]}$ 测定蔗糖酶活性; 用昆 布多糖比色法测定 $\beta-1,3$-葡聚糖酶活性 ${ }^{[15]}$ 。用国产 Y162A型束纤维强力机测定 $3.2 \mathrm{~mm}$ 隔距比强度, 6次 重复, 并用中国纤维检验局的标准棉样品修正。

\section{3 数据分析方法}

用Microsoft Excel和SPSS 16.0软件分析数据。

\section{2 结果与分析}

\section{1 花铃期渍水对棉纤维比强度的影响}

表 2 表明, 花铃期渍水处理显著降低成熟期纤 维比强度 $(P<0.05)$ 。与对照相比, 渍水 $7 \mathrm{~d}$ 处理起始 于花后 $0 \mathrm{~d}$ 和 $10 \mathrm{~d}$, 成熟期纤维比强度分别下降 4.99\% 和 3.57\% (2009); 渍水 $14 \mathrm{~d}$ 处理起始于花后 $0 \mathrm{~d}$ ，成 熟期纤维比强度下降 6.87\% (2007)和 6.01\% (2009), 起始于花后 $10 \mathrm{~d}$ 时下降 10.03\% (2007)和 9.27\% (2009)。表明渍水 $7 \mathrm{~d}$ 和渍水 $14 \mathrm{~d}$ 处理分别对渍水起 始于花后 $0 \mathrm{~d}$ 和花后 $10 \mathrm{~d}$ 棉铃纤维比强度影响较大。 渍水处理间相比, 成熟期纤维比强度渍水 $7 \mathrm{~d}$ 处理 比渍水 $14 \mathrm{~d}$ 处理高 $1.1 \% \sim 6.3 \%$ 。

\section{2 花铃期渍水对纤维物质含量的影响}

\subsection{1 蔗糖含量 由图 1 可见, 对照纤维蔗糖含} 量呈单峰曲线变化, 峰值在花后 $17 \mathrm{~d}$ 。渍水处理降 低纤维加厚发育期熫糖含量。渍水起始于花后 $0 \mathrm{~d}$ 时, 渍水 $7 \mathrm{~d}$ 和渍水 $14 \mathrm{~d}$ 处理蔗糖含量分别于花后 17 31 d 和 17 24 d 显著降低 $(P<0.05)$; 起始于花后 $10 \mathrm{~d}$ 时于花后 $24 \sim 31 \mathrm{~d}$ 显著降低 $(P<0.05)$ 。渍水处理 间相比, 渍水起始于花后 $0 \mathrm{~d}$ 时, 花后 17 31 d 蔗糖 含量以渍水 $14 \mathrm{~d}$ 处理较高; 起始于花后 $10 \mathrm{~d}$ 时, 花 后 24 38 d 蔗糖含量以渍水 $7 \mathrm{~d}$ 处理较高。

2.2.2 $\beta-1,3$-葡聚糖含量 纤维 $\beta-1,3$-葡聚糖含量呈 单峰曲线变化, 峰值在花后 $17 \mathrm{~d}$ 或 $24 \mathrm{~d}$ (图 1)。渍水 处理降低了峰值期 $\beta-1,3$-葡聚糖含量, 如渍水起始于 花后 $0 \mathrm{~d}$ 时, 渍水 $7 \mathrm{~d}$ 和 $14 \mathrm{~d}$ 处理 $\beta$-1,3-葡聚糖含量分 别于花后 $17 \sim 31 \mathrm{~d}$ 和 17 $24 \mathrm{~d}$ 降低 $(P<0.05)$ 。渍水处理 间相比, 渍水起始于花后 $0 \mathrm{~d}$ 时, 花后 24 31 d $\beta-1,3-$ 葡聚糖含量以渍水 $14 \mathrm{~d}$ 处理较高; 起始于花后 $10 \mathrm{~d}$ 时, 花后 $24 \mathrm{~d}$ 后 $\beta-1,3$-葡聚糖含量以渍水 $7 \mathrm{~d}$ 处理较高。 
2007
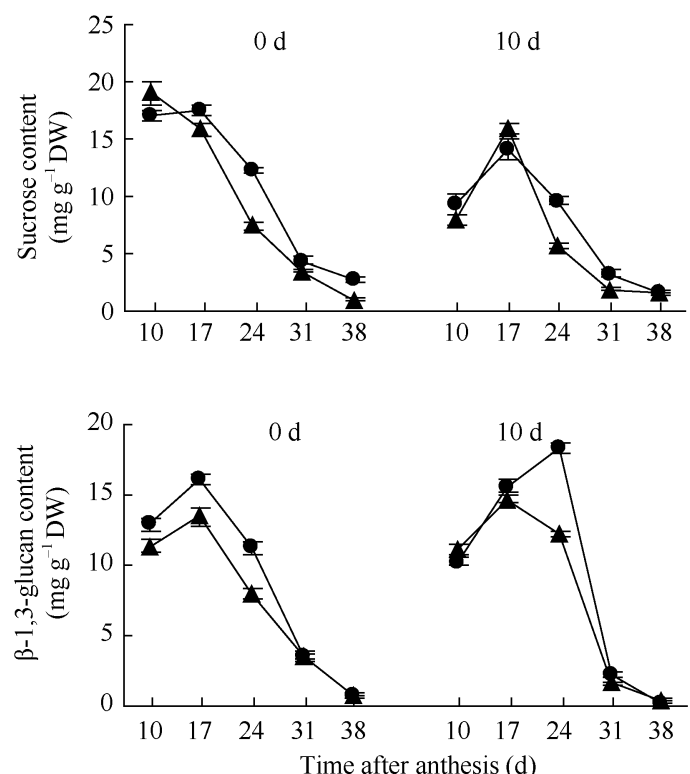

2009

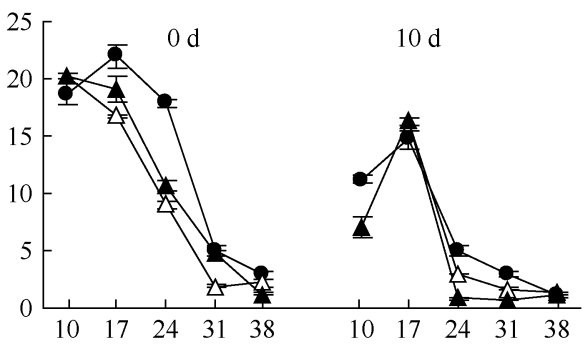

$0 \mathrm{~d}$

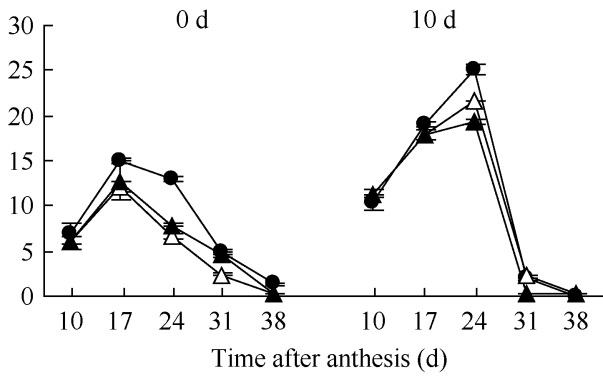

- Control $\Delta$ Waterlogging 7 days $\boldsymbol{\Delta}$ Waterlogging 14 days

图 1 花铃期渍水对棉纤维蔗糖和 $\beta$-1,3-葡聚糖含量的影响

Fig. 1 Effects of waterlogging on changes of sucrose and $\beta$-1,3-glucan contents in fiber during flowering and bolling stage

2.2.3 纤维素含量 纤维素含量呈慢-快-慢的累 积动态, 用 Logistic 模型对纤维素累积进行模拟, 得 到纤维素含量累积拟合方程均达到极显著水平。表 1 表明, 渍水处理的纤维素含量理论最大值随渍水 持续期延长而降低; 纤维素含量快速增长期提前而 持续期缩短, 渍水 $7 \mathrm{~d}$ 处理纤维素最大累积速率均 增加, 渍水 $14 \mathrm{~d}$ 处理起始于花后 $0 \mathrm{~d}$ 时最大速率增 加而起始于花后 $10 \mathrm{~d}$ 时降低。渍水处理间相比, 随
渍水持续期延长, 纤维素快速累积持续时间延长, 但最大速率降低, 纤维素累积量降低。

2.3 花铃期渍水对纤维蔗糖代谢相关酶活性的 影响

2.3.1 蔗糖合酶(SS)和蔗糖磷酸合酶(SPS) 由 图 2 可见, SS 活性呈先降后升的变化, 渍水处理对 其影响与渍水持续期及起始时花后时间有关。渍水 起始于花后 $0 \mathrm{~d}$ 时, 渍水 $7 \mathrm{~d}$ 和 $14 \mathrm{~d}$ 处理 $\mathrm{SS}$ 活性分

表 1 花铃期渍水对纤维素累积特征值的影响

Table 1 Effect of waterlogging on the characteristics of cellulose accumulation in fiber during flowering and bolling stage

\begin{tabular}{|c|c|c|c|c|c|c|c|c|}
\hline $\begin{array}{l}\text { 年份 } \\
\text { Year } \\
\end{array}$ & $\begin{array}{c}\text { 花后天数 } \\
\text { Days after anthesis }\end{array}$ & $\begin{array}{c}\text { 处理 } \\
\text { Treatment }\end{array}$ & $\begin{array}{l}\text { 模型 } \\
\text { Model }\end{array}$ & $R^{2}$ & $\begin{array}{c}t_{1} \\
\text { (d) }\end{array}$ & $\begin{array}{l}t_{2} \\
\text { (d) }\end{array}$ & $\begin{array}{c}T \\
\text { (d) }\end{array}$ & $\begin{array}{c}V_{\max } \\
\left(\mathrm{g} \mathrm{d}^{-1}\right) \\
\end{array}$ \\
\hline \multirow[t]{4}{*}{2007} & $0 \mathrm{~d}$ & 对照 Control & $C=89.63 /\left(1+37.92 \mathrm{e}^{-0.18 t}\right)$ & $0.9918^{* *}$ & 13.8 & 23.3 & 9.5 & 3.94 \\
\hline & & 渍水 $14 \mathrm{~d}$ WL $14 \mathrm{~d}$ & $C=80.17 /\left(1+59.01 \mathrm{e}^{-0.21 t}\right)$ & $0.9834^{* *}$ & 13.3 & 21.2 & 7.8 & 4.30 \\
\hline & $10 \mathrm{~d}$ & 对照 Control & $C=88.13 /\left(1+55.07 \mathrm{e}^{-0.19 t}\right)$ & $0.9947^{* *}$ & 14.4 & 23.1 & 8.7 & 4.27 \\
\hline & & 渍水 $14 \mathrm{~d}$ WL $14 \mathrm{~d}$ & $C=76.71 /\left(1+43.89 \mathrm{e}^{-0.20 t}\right)$ & $0.9903^{* *}$ & 12.6 & 20.9 & 8.3 & 3.89 \\
\hline \multirow[t]{6}{*}{2009} & $0 \mathrm{~d}$ & 对照 Control & $C=88.57 /\left(1+44.76 \mathrm{e}^{-0.18 t}\right)$ & $0.9650^{* *}$ & 14.7 & 24.0 & 9.3 & 4.03 \\
\hline & & 渍水 $7 \mathrm{~d}$ WL $7 \mathrm{~d}$ & $C=81.50 /\left(1+41.40 \mathrm{e}^{-0.19 t}\right)$ & $0.9869^{* *}$ & 14.3 & 21.6 & 7.4 & 4.64 \\
\hline & & 渍水 $14 \mathrm{~d}$ WL $14 \mathrm{~d}$ & $C=80.28 /\left(1+79.26 \mathrm{e}^{-0.22 t}\right)$ & $0.9752^{* *}$ & 14.4 & 22.1 & 7.7 & 4.39 \\
\hline & $10 \mathrm{~d}$ & 对照 Control & $C=85.47 /\left(1+66.87 \mathrm{e}^{-0.20 t}\right)$ & $0.9787^{* *}$ & 14.7 & 23.0 & 8.3 & 4.34 \\
\hline & & 渍水 $7 \mathrm{~d}$ WL $7 \mathrm{~d}$ & $C=79.12 /\left(1+108.58 \mathrm{e}^{-0.25 t}\right)$ & $0.9887^{* *}$ & 13.8 & 20.5 & 6.7 & 4.98 \\
\hline & & 渍水 $14 \mathrm{~d}$ WL $14 \mathrm{~d}$ & $C=75.89 /\left(1+50.07 \mathrm{e}^{-0.20 t}\right)$ & $0.9948^{* *}$ & 13.3 & 21.6 & 8.3 & 3.85 \\
\hline
\end{tabular}

$C$ : 纤维素含量; $T$ : 纤维素含量快速增长期历时; $t_{1}, t_{2}$ : 纤维素含量快速增长期开始和结束的时间; $V_{\text {max }}$ : 纤维素含量最大增长速率。

$C$ : cellulose content; $T$ : period for cellulose content speed increasing; $t_{1}, t_{2}$ : time for starting and terminating of cellulose content increasing; $V_{\max }$ : maximal speed of cellulose content increasing; WL $7 \mathrm{~d}$ : waterlogging 7 days; WL 14 d: waterlogging 14 days; TAA: time after anthesis; ${ }^{* *} P<0.01\left(n=5, R_{0.01}^{2}=0.9191\right)$. 
别于花后 $38 \mathrm{~d}$ 和 $24 \sim 38 \mathrm{~d}$ 增加 $(P<0.05)$; 而起始于花 后 $10 \mathrm{~d}$ 时分别于花后 24 31 d 增加 $(P<0.05)$ 和花后 $31 \mathrm{~d}$ 后降低 $(P<0.05)$ 。渍水处理间相比, 起始于花后 $0 \mathrm{~d}$ 时, 花后 24 31 d SS 活性以渍水 $14 \mathrm{~d}$ 处理较高; 而起始于花后 $10 \mathrm{~d}$ 时则以渍水 $7 \mathrm{~d}$ 处理较高。渍水 对纤维 SPS 活性的影响与 SS 相似。

\subsection{2 蔗糖酶活性蔗糖酶活性随花后时间增加} 呈下降动态(图 2)。渍水起始于花后 $0 \mathrm{~d}$ 时, 花后 17 24 d 纤维蔗糖酶活性显著降低 $(P<0.05)$; 起始于 花后 $10 \mathrm{~d}$ 时, 花后 $10 \sim 17 \mathrm{~d}$ 蔗糖酶活性显著降低 $(P<0.05)$ 。渍水处理间差异小。

2.3.3 $\beta-1,3$-葡聚糖酶活性 由图 2 可见, $\beta-1,3-$ 葡聚糖酶活性随花后时间增加呈下降动态。渍水处
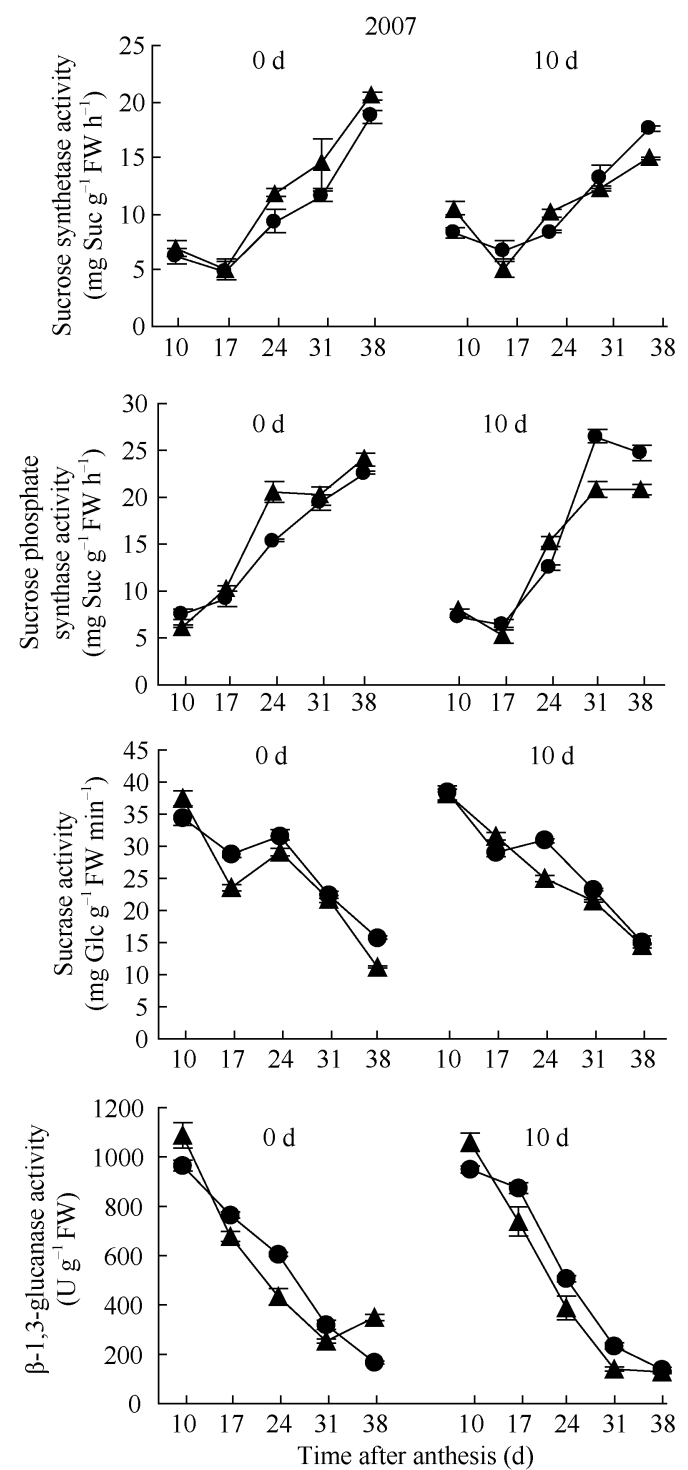

- Control $\Delta$ Waterlogging 7 days
理降低了加厚发育期纤维 $\beta-1,3$-葡聚糖酶活性。如渍 水起始于花后 $10 \mathrm{~d}$ 时, 渍水 $7 \mathrm{~d}$ 和 $14 \mathrm{~d}$ 处理 $\beta-1,3$ 葡聚糖酶活性分别于花后 17 24 d 和 17 31 d 显著降 低 $(P<0.05)$ 。渍水处理间差异与 $\beta-1,3$-葡聚糖含量差 异相似。

2.4 纤维比强度与纤维发育相关物质和酶活的 关系

表 2 表明, 与对照相比, 渍水处理花后 17 38 d 蔗糖、 $\beta-1,3$-葡聚糖含量均值降低。渍水 $7 \mathrm{~d}$ 处理起 始于花后 $0 \mathrm{~d}$ 时花后 17 38 d 蔗糖和 $\beta-1,3$-葡聚糖含 量均值分别降低 $37.44 \%$ 和 $36.30 \%$; 起始于花后 $10 \mathrm{~d}$ 时分别降低 $42.64 \%$ 和 $8.59 \%$ 。渍水 $14 \mathrm{~d}$ 处理起始于 花后 $0 \mathrm{~d}$ 时花后 17 38 d 蔗糖和 $\beta-1,3$-葡聚糖含量均
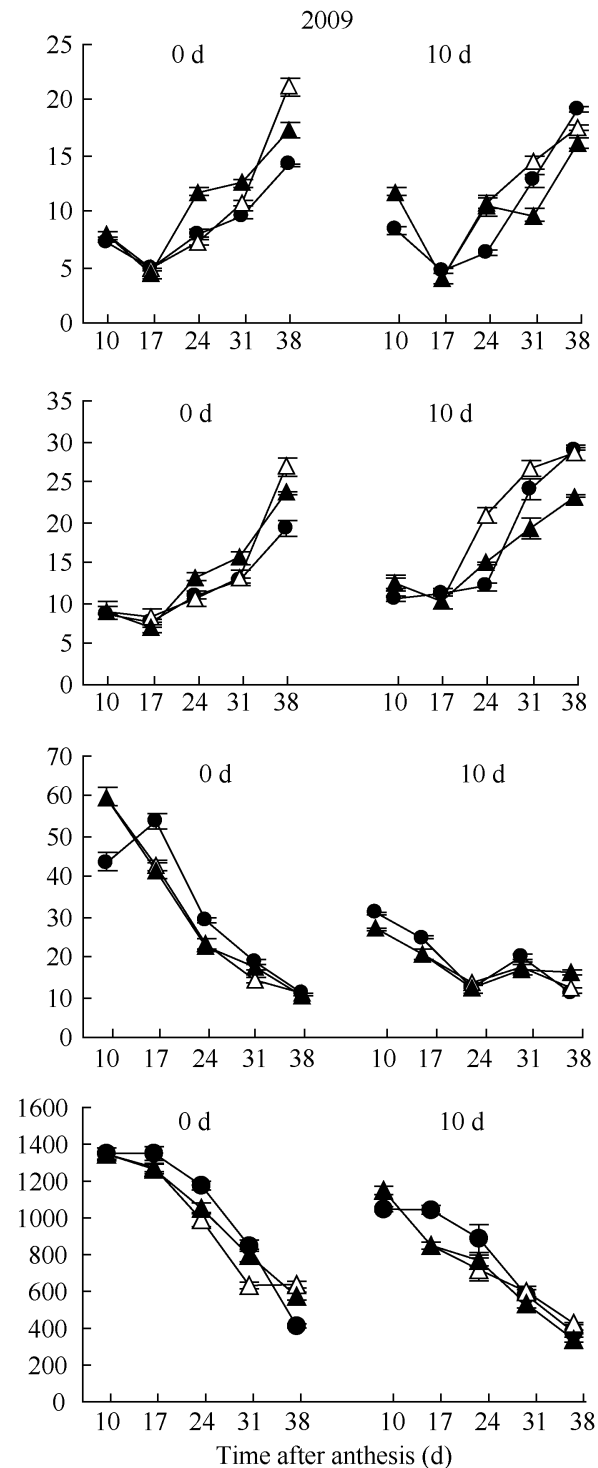

图 2 花铃期渍水对棉纤维糖代谢相关酶活性的影响

Fig. 2 Effects of waterlogging on enzyme activity associated with sugar metabolism in fiber during flowering and bolling stage 


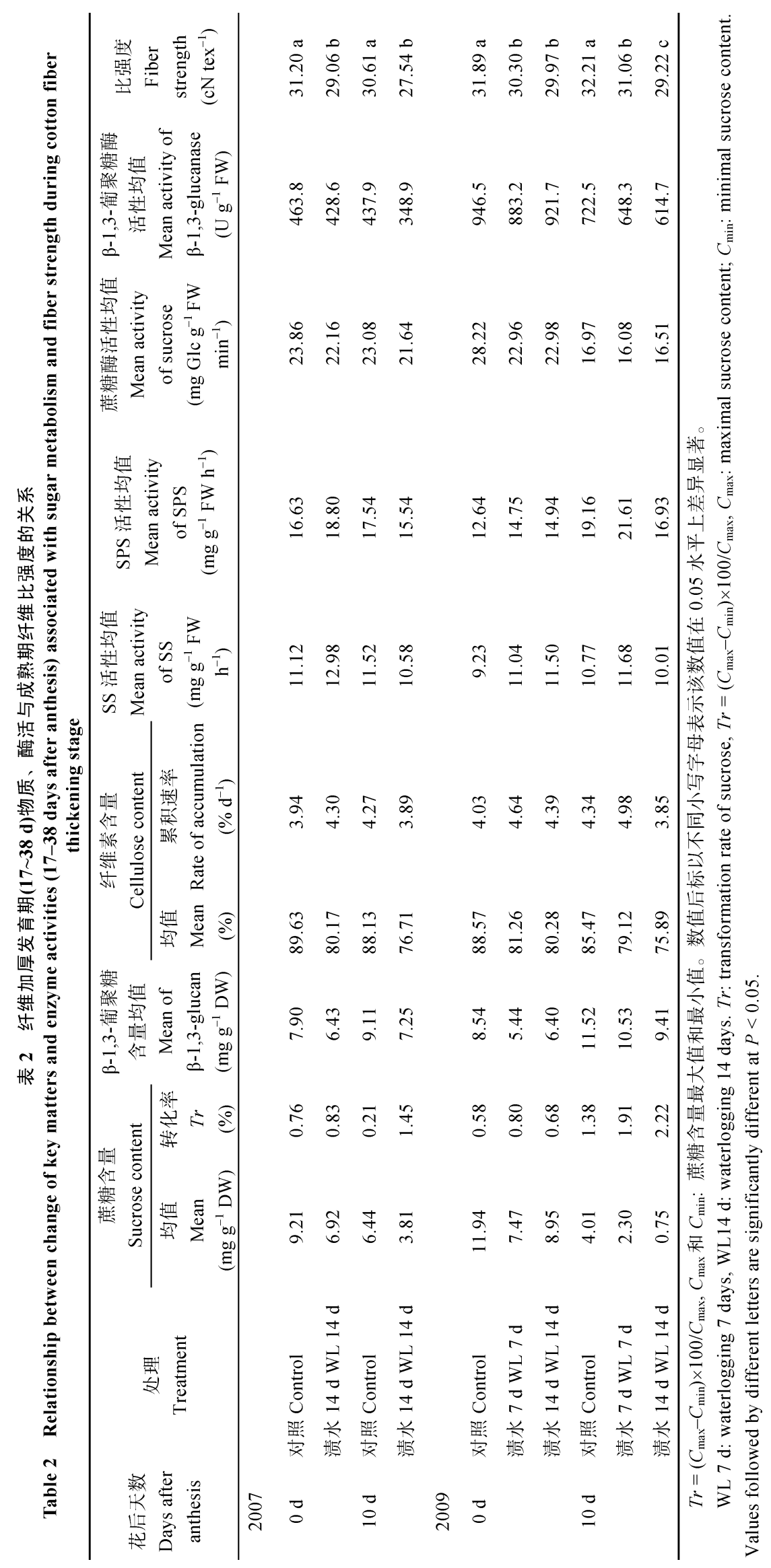


值分别降低 25.04\%和 $25.06 \%$ (2009); 起始于花后 $10 \mathrm{~d}$ 时分别降低 $81.30 \%$ 和 $18.32 \%$ (2009)。渍水处理 间相比, 渍水起始于花后 $0 \mathrm{~d}$ 时, 纤维蔗糖和 $\beta-1,3-$ 葡聚糖含量均值以渍水 $14 \mathrm{~d}$ 处理较高; 起始于花后 $10 \mathrm{~d}$ 时则以渍水 $7 \mathrm{~d}$ 处理较高。结合前述渍水处理 对纤维比强度的影响, 可见渍水下蔗糖含量下降与 纤维比强度的结果一致。表 2 还表明, 渍水条件下 熫糖转化率随渍水持续期延长增加; 渍水 $14 \mathrm{~d}$ 处理 起始于花后 $10 \mathrm{~d}$ 时纤维素快速累积期最大速率降低, 其他处理均增加; 纤维素含量和纤维比强度均随渍 水持续期延长降幅增大。表明渍水下蔗糖转化并非 都用于纤维素的合成, 纤维素过快和过慢累积均不 利于提高纤维比强度。

与对照相比, 渍水 $7 \mathrm{~d}$ 处理起始于花后 $0 \mathrm{~d}$ 时花 后 17 38 d 纤维 SS 和 SPS 活性均值分别增加 19.61\% 和 $16.69 \%$, 起始于花后 $10 \mathrm{~d}$ 时分别增加 $8.45 \%$ 和 $12.79 \%$ 。渍水 $14 \mathrm{~d}$ 处理起始于花后 $0 \mathrm{~d}$ 时花后 17 38 d 纤维 SS 和 SPS 活性均值分别增加 $24.60 \%$ 和 $18.20 \%$ (2009), 起始于花后 $10 \mathrm{~d}$ 时分别降低 7.06\%和 $11.64 \%$ (2009), 表明 SPS 和 SS 活性变化与渍水持续期和起 始时间有关。SPS 和 SS 活性增加时受渍害较轻, 纤 维比强度下降 3.57\% 6.86\%; SS、SPS 活性降低时受 渍害较重, 比强度下降 9.28\% 10.03\%。此外, 渍水处 理的蔗糖酶和 $\beta-1,3$-葡聚糖酶活性均值呈降低趋势。

\section{3 讨论}

蔗糖是纤维糖代谢的起始底物, 胡宏标等 ${ }^{[7]}$ 研 究表明纤维发育过程中蔗糖含量和转化率高有利于 纤维比强度的提高。本试验渍水条件下由于棉铃对 位叶碳源持续供给能力降低(另文发表), 花后 17 38 d 纤维蔗糖含量均值比对照降低 $24.86 \% \sim 81.30 \%$, 且 不同处理蔗糖含量下降的幅度与纤维比强度下降的 幅度一致, 纤维加厚发育期 $\beta-1,3$-葡聚糖含量也下 降。因此, 加厚发育期纤维蔗糖、 $\beta-1,3$-葡聚糖含量 降低是纤维比强度降低的原因。与 Pettigrew 等 ${ }^{[19]}$ 遮阴下纤维加厚发育期(花后 $21 \mathrm{~d}$ )蔗糖含量降低影 响最终纤维强度的观点一致, 与低温下蔗糖转化率 降低 ${ }^{[12]}$ 是棉花纤维素合成受阻的主要原因结果不太 一致。本试验渍水处理蔗糖转化率增加, 致使纤维 素快速累积期提前、但持续期缩短, 不同处理纤维 素累积最大速率增加或降低, 推测与受渍害程度有 关。表明纤维素平缓累积有利于纤维比强度提高, 而过快 ${ }^{[4,7]}$ 、过慢累积均不利于纤维比强度提高。渍
水对纤维物质的影响与渍水持续期及起始时间有关。 渍水起始于花后 $0 \mathrm{~d}$ 时, 纤维蔗糖和 $\beta-1,3$-葡聚糖含 量以渍水 $7 \mathrm{~d}$ 处理受影响较大; 起始于花后 $10 \mathrm{~d}$ 时, 则以渍水 $14 \mathrm{~d}$ 处理受影响较大, 而纤维素含量、纤维 比强度随渍水持续期延长而降低。植物在逆境条件下 体内的碳水化合物首先用于维持呼吸和生存能量需 求 ${ }^{[20]}$, 推测渍水下纤维物质并非都用于纤维素合成, 随渍水持续期延长, 用于维持生存代谢的消耗增多。

纤维发育相关物质受酶活调控。已有的研究表 明纤维加厚发育期 SS 活性增加的同时 SPS 活性也 增加, 直接或间接影响纤维素合成 ${ }^{[8]}$ 。另有研究发现, SS 是渍水条件下蔗糖降解的主要酶 ${ }^{[21-23]}$, 可为植物 在低氧胁迫下提供足够的糖 ${ }^{[24]}$ 。本试验中渍水 $7 \mathrm{~d}$ 与渍水 $14 \mathrm{~d}$ (起始于花后 $0 \mathrm{~d}$ )处理花后 17 38 d 纤维 SS 和 SPS 活性均值分别增加 $8.45 \%$ 24.59\% 和 $12.79 \%$ 18.20\%，但最终纤维素累积量降低，表明有 纤维素合成以外的碳源消耗途径存在。Haigler 等 ${ }^{[8,25]}$ 推测逆境下碳源供应减少且膜结合型 SS 向可溶型 转化, 增加细胞质中游离 UDPG 浓度用于维持基本 代谢过程, 纤维素停止高速合成。纤维发育中蔗糖 主要来源于棉铃对位叶, 渍水下棉铃对位叶熫糖代 谢酶活性均被激活，蔗糖累积而铃重降低(另文已发 表)。可见, 渍水条件下棉铃对位叶、棉铃中蔗糖代 谢均被激活但生成碳源并非都用于棉铃发育。花铃 期渍水条件下，通过栽培措施补给碳源、促进碳源 有效利用有利于改善铃重和纤维品质。本试验中, 渍水 $7 \mathrm{~d}$ 处理起始于花后 $10 \mathrm{~d}$ 时纤维 SS、SPS 活性 响应快于起始于花后 $0 \mathrm{~d}$ 时; 渍水 $14 \mathrm{~d}$ 处理起始于 花后 $0 \mathrm{~d}$ 时, 花后 17 38 d SS 和 SPS 活性均值增加 而起始于花后 $10 \mathrm{~d}$ 时降低。推测 SS 与 SPS 活性响 应渍水的变化与受渍害程度有关。受渍害较轻时 SS 和 SPS 活性响应快且酶活增加、纤维比强度下降幅 度较小; 受渍害较重时酶活性降低, 纤维比强度下 降幅度大。此外, 渍水条件下根系是直接受害的器 官, 根部的碳水化合物大部分用于储存, 是恢复生 长阶段根和叶重新生长的重要物质来源 ${ }^{[26]}$ 。因此, 生产中及时清沟理墑, 促进根部恢复生长是产量和 品质提高的保证。

\section{4 结论}

花铃期渍水下，纤维加厚发育期蔗糖、 $\beta-1,3$-葡 聚糖含量降低; 纤维 SS 和 SPS 活性受渍较轻条件下 被激活而受渍较重条件下降低，蔗糖酶、 $\beta-1,3$-葡聚 
糖酶活性也降低。渍水下碳源供应不足, 糖代谢消 耗增加或受抑制是最终纤维比强度降低的原因。

\section{References}

[1] Reddy K R, Davidonis G H, Johnson A S, Vinyard B T. Temperature regime and carbon dioxide enrichment alter cotton boll development and fiber properties. Agron J, 1999, 91: 851-858

[2] 刘瑞显, 郭文琦, 陈兵林, 周治国, 孟亚利. 氮素对花铃期干 旱再复水后棉花纤维比强度形成的影响. 植物营养与肥料学 报, 2009, 15: 662-669

Liu R X, Guo W Q, Chen B L, Zhou Z G, Meng Y L. Effects of nitrogen on cotton fiber strength formation under water stress and rewatering during the flowering and boll-forming stage. Plant Nutr Fert Sci, 2009, 15: 662-669 (in Chinese with English abstract)

[3] 刘继华, 尹承佮, 于凤英, 孙清荣, 王永民, 贾景农, 边栋材, 陈学留. 棉花纤维强度的形成机理与改良途径. 中国农业科 学, 1994, 27(5): 10-16

Liu J H, Yin C Y, Yu F Y, Sun Q R, Wang Y M, Jia J N, Bian D C, Chen X L. Formation mechanism and improvement approach of cotton (Gossypium) fiber strength. Sci Agric Sin, 1994, 27(5): 10-16 (in Chinese with English abstract)

[4] 束红梅, 王友华, 陈兵林, 胡宏标, 张文静, 周治国. 棉花纤 维素累积特性的基因型差异及与纤维比强度形成的关系. 作 物学报, 2007, 33: 921-926

Shu H M, Wang Y H, Chen B L, Hu H B, Zhang W J, Zhou Z G. Genotypic differences in cellulose accumulation of cotton fiber and its relationship with fiber strength. Acta Agron Sin, 2007, 33: 921-926 (in Chinese with English abstract)

[5] Doblin M S, Kurek I, Jacok W D. Cellulose biosynthesis in plants: from genes to rosettes. Plant Cell Physiol, 2002, 43: 1407-1420

[6] Shu H M, Wang Y H, Zhang W J, Zhou Z G. Activity changes of enzymes associated with fiber development and relationship with fiber specific strength in two cotton cultivars. Acta Agron Sin, 2008, 34: 437-446

[7] 胡宏标, 张文静, 王友华, 陈兵林, 周治国. 棉纤维加厚发育 相关物质对纤维比强度的影响. 西北植物学报, 2007, 27: 726-733

Hu H B, Zhang W J, Wang Y H, Chen B L, Zhou Z G. Matters related with cotton fiber thickening development and fiber strength. Acta Bot Boreali-Occident Sin, 2007, 27: 726-733 (in Chinese with English abstract)

[8] Haigler C H, Milka I D, Hogan P S, Salnkov V V, Hwang S, Martin K, DelMer D P. Carbon partitioning to cellulose synthesis. Plant Mol Biol, 2001, 47: 29-51

[9] Michelle B V, Haigler C H. Sucrose-phosphate synthase activity rises in correlation with high-rate cellulose synthesis in three heterotrophic systems. Plant Physiol, 2001, 127: 1234-1242

[10] Koch K. Sucrose metabolism: regulatory mechanisms and pivotal roles in sugar sensing and plant development. Curr Opin Plant Biol, 2004, 7: 235-246

[11] Shimizu Y, Aotsuka S, Hasegawa O, Kawada T, Sakuno T, Sakai F, Hayashi T. Changes in levels of mRNAs for cell wall-related enzymes in growing cotton fiber cells. Plant Cell Physiol, 1997, 38: $375-378$

[12] Shu H M, Zhou Z G, Xu N Y, Wang Y H, Zheng M. Sucrose me- tabolism in cotton (Gossypium hirsutum L.) fiber under low temperature during fiber development. Eur J Agron, 2009, 31: 61-68

[13] 冯营，赵新华，王友华，马溶慧，周治国. 棉纤维发育过程中 糖代谢生理特征对氮素的响应及其与纤维比强度形成的关系. 中国农业科学, 2009, 42: 93-102

Feng Y, Zhao X H, Wang Y H, Ma R H, Zhou Z G. Responses of carbohydrate metabolism to nitrogen in cotton fiber development and its relationships with fiber strength formation. Sci Agric Sin, 2009, 42: 93-102 (in Chinese with English abstract)

[14] 马溶慧, 许乃银, 张传喜, 李文峰, 冯营, 屈磊, 王友华, 周治 国. 氮素调控棉花纤维蔗糖代谢及纤维比强度的生理机制. 作物学报, 2008, 34: 2143-2151

Ma R H, Xu N Y, Zhang C X, Li W F, Feng Y, Qu L, Wang Y H, Zhou Z G. Physiological mechanism of sucrose metabolism in cotton fiber and fiber strength regulated by nitrogen. Acta Agron Sin, 2008, 34: 2143-2151 (in Chinese with English abstract)

[15] 汤章城主编. 现代植物生理学实验指南. 北京: 科学出版社, 1999. pp 126-128

Tang Z C ed. Modern Laboratory Manual of Plant Physiology. Beijing: Science Press, 1999. pp 126-128 (in Chinese)

[16] Köhle H, Jeblick W, Poten F, Blaschek W, Kauss H. Chitosanelicited callose synthesis in soybean cells as a $\mathrm{Ca}^{2+}$-dependent process. Plant Physiol, 1985, 77: 544-551

[17] Updegraff D M. Semimicro determination of cellulose in biological materials. Anal Biochem, 1969, 32: 420-424

[18] Konishi L, Nakai T, Sakai F, Hayashi T. Formation of callose from sucrose in cotton fiber microsomal membranes. Jpn Wood Res Soc, 2001, 47: 331-335

[19] Pettigrew W T. Environmental effects on cotton fiber carbohydrate concentration and quality. Crop Sci, 2001, 41: 1108-1113

[20] Hook D D, Brown C L. Root adaptations and relative flood tolerance of five hardwood species. Forensic Sci, 1973, 19: 225-229

[21] Wäfler U, Meier H. Enzyme activities in developing cotton fibers. Plant Physiol Biochem, 1994, 32: 697-702

[22] Sairam R K, Dharmar K, Chinnusamy V, Meena R C. Waterlogging-induced increase in sugar mobilization, fermentation, and related gene expression in the roots of mungbean (Vigna radiata). J Plant Physiol, 2009, 166: 602-616

[23] Kumutha D, Sairam R K, Ezhilmathi K, Chinnusamy V, Meena R C. Effect of waterlogging on carbohydrate metabolism in pigeon pea (Cajanus cajan L.): upregulation of sucrose synthase and alcohol dehydrogenase. Plant Sci, 2008, 175: 706-716

[24] Springer B, Werr W, Starlinger P, Bennett D C, Zokolica M, Freeling M. The shrunken gene on chromosome 9 of Zea mays L. is expressed in various plant tissues and encodes an anaerobic protein. Mol Gen Genet, 1986, 205: 461-468

[25] Haigler C H. Substrate supply for cellulose synthesis and its stress sensitivity in the cotton fiber. In: Brown R M Jr, Saxena I, eds. Cellulose: Molecular and Structural Biology, Springer: New York, 2007. pp 147-168

[26] 施美芬, 曾波, 申建红, 类淑桐, 朱智, 刘建辉. 植物水淹适 应与碳水化合物的相关性. 植物生态学报, 2010, 34: 855-866 Shi M F, Zeng B, Shen J H, Lei S T, Zhu Z, Liu J H. A review of the correlation of flooding adaptability and carbohydrates in plants. Chin J Plant Ecol, 2010, 34: 855-866 (in Chinese with English abstract) 